\title{
Composite methodology to prevent ship propeller erosion
}

\author{
Toni Llull $^{\text {a, *, Anna Mujal-Colilles }}{ }^{\text {b }}$, Marcel·la Castells ${ }^{c}$, Xavier Gironella ${ }^{a}$ \\ ${ }^{a}$ Maritime Engineering Laboratory, Department of Civil and Environmental Engineering, UPC-Barcelona Tech, Barcelona, Spain \\ ${ }^{\mathrm{b}}$ Maritime Engineering Laboratory, Department of Nautical Science and Engineering, UPC-Barcelona Tech, Barcelona, Spain \\ ${ }^{\mathrm{c}}$ Department of Nautical Science and Engineering, UPC-Barcelona Tech, Barcelona, Spain
}

\section{A R T I C L E I N F O}

\section{Keywords:}

Harbour management

Propeller induced scour

Ship manoeuvre

Numerical simulator

\begin{abstract}
A B S T R A C T
The jet flow generated by manoeuvring ships nearby vertical structures is known to erode the seabed sediment but is still difficult to predict the effects of a particular ship operating in a harbour basin. This paper presents a methodology to quantify the scouring action generated by ship's propellers combining field and real data with a manoeuvre numerical simulator testing some of the most commonly used formulas for maximum scouring depth prediction. From the real manoeuvres, analysed through Automatic Identification System (AIS) data, the manoeuvre patterns are identified to be later reproduced at the simulator, thus obtaining the propulsion system behaviour to apply the formulae and to estimate the maximum erosion depth expected in a harbour basin. The obtained results are validated with field data from bathymetries and Acoustic Doppler Velocimeter (ADV). Results show the arrival and departure manoeuvre sections where the vessel is potentially harmful. The different formulae applied yielded results in accordance with the provided bathymetry of the study area in terms of maximum erosion depth. Also, the areas of maximum expected seabed velocity are coincident with the areas where the maximum scour is observed in the bathymetry.
\end{abstract}

\section{Introduction}

Coastal infrastructures are an increasing focus of interest due to the evolution of shipping industry over the last decades. Up to $80 \%$ of the world trade is carried by the sea (Becker et al., 2013), rising the pressure to harbours and ports. In particular, the increase of maritime transport leading to a global increment of ship routes, ship size, and propulsion systems is affecting docking infrastructures designed to host smaller and less powerful ships with lower docking frequencies, mostly in cases of ferry ships or cruise ships, equipped with transversal propellers which allow them to manoeuvre without the assistance of tug boats. The use of more powerful propulsion systems is causing severe damages to berthing structures regardless of their design (open quays or quay walls). These damages are mainly related to scouring effects of the stern propellers flow which create a hole that can reach a maximum depth of the order of magnitude of the stern propellers diameter in a few months as reported by (Mujal-Colilles et al., 2017a). At the same time, the sediment eroded at the toes of the berthing structures settles along other areas of the harbour basin, reducing its depth, capacity and operability. Moreover, if the seabed contains a capped layer of coarser grain sizes to protect contaminated sediment below, (Ebbesmeyer et al., 1995), the effects of stern propellers in the harbour basin can be environmental and structural at the same time, (Hayes et al., 2006; Wang et al., 2006).

The relevant research related to propeller effects on harbour sediment beds started at the mid decades of the 20th century with (Albertson et al., 1950). They proposed that the velocity distribution at any section of the submerged jet can be described by a Gaussian normal probability function. An equation was proposed, dependent on the efflux velocity, $U_{0}$, to obtain the velocity distribution at any section in the zone of flow establishment. The $U_{O}$ is defined as the maximum value of the axial velocity taken from a time-averaged velocity distribution downstream of the propeller plane (Ryan, 2002), and is obtained from Bernoulli's and mass conservation equations from an ideal actuator disk. Later (Blaauw and van de Kaa, 1978), performed experimental tests on scouring effects, fixing the minimum Reynolds numbers of the propeller and jet flow to avoid scaling effects, and proposed a new expression for the efflux velocity as a function of the installed power. The guidelines of the World Association for Waterborne Transport Infrastructure, (PIANC, 2015), refer to the equations proposed by (Blaauw and van de Kaa, 1978) as the Dutch method including their expressions for the axial

\footnotetext{
* Corresponding author.

E-mail addresses: antoni.llull.marroig@upc.edu (T. Llull), anna.mujal@upc.edu (A. Mujal-Colilles), mcastells@cen.upc.edu (M. Castells), xavi.gironella@upc.edu (X. Gironella).
} 
velocity evolution along the propeller axis of symmetry. Using laboratory experiments, (Verheij, 1983), proposed the first equations to relate the maximum scouring depth, area and volume as a function of variables related to both the propeller and the harbour area conditions (sediment diameter and clearance distance). Parallel in time, other scientists tested and developed formulas for the maximum bed velocity produced by a propeller mainly using laboratory experiments with single propellers (Blokland and Smedes, 1996; Fuehrer et al., 1987; Hamill, 1987; Stewart, 1992). However, the equations proposed by the former scientists were based on propellers acting in a free space, without any vertical or inclined wall (Hamill et al., 1999). performed a set of laboratory experiments concluding that the erosion due to the action of ship propeller increases substantially when a vertical wall interacts with the flow, particularly close to the toe of the vertical wall (Ryan et al., 2013). improved the former equation using other analytical techniques to better fit the experimental results. Similarly (Yuksel et al., 2019), performed an experimental study on scour near quay wall, providing also with a new equation to obtain the maximum scouring depth due to confined flow erosion. Recently, (Wei and Chiew, 2019), performed an exhaustive study on propeller jet flow impingement to a vertical wall by using 3D PIV technique.

Twin propeller effects have been extrapolated from single propeller expressions, as proposed by (PIANC, 2015). According to (PIANC, 2015), (Fuehrer et al., 1981) calibrated the equation of axial velocity evolution of (Albertson et al., 1950) for twin propellers, but the influence of twin propellers in the maximum erosion depth is still unknown (Mujal-Colilles et al., 2017b). applied the formulas to predict efflux velocity to twin propeller experiments and concluded that the expression for axial velocity of (Blaauw and van de Kaa, 1978) was predicting the results for twin propellers fairly good, whereas bed velocity for twin propeller models were better fitted by the formula of (Fuehrer et al., 1981). Recently, other authors (Cui et al., 2019; Jiang et al., 2019; Yew et al., 2017) studied the twin propeller wash and its effect over the seabed in experimental models with mobile seabed, also proposing new equations to predict the scour due to single and twin propeller jets in unconfined condition.

International guidelines such as (BAW, 2010; PIANC, 2015) propose different prevention and protection systems to avoid the scour produced by propellers in both the navigation channel and the harbour basin. Formulas are based on previous estimation of efflux velocity and bed velocity, using Shields criteria as the threshold for resuspension. As reported by (Mujal-Colilles et al., 2017a) most of the existing equations overestimate, by far, real results of maximum scouring depth. This may be due to the scale effects induced by experimental formulas with few contrasts to reality. Besides, the overestimation can come from the fact that only single propellers have been tested avoiding also the inclusion of different manoeuvre characteristics (Mujal-Colilles et al., 2018). experimentally studied the effects of twin propellers wash over the seabed sediment during the docking and undocking manoeuvres by combining ahead/astern rotation of the propellers in a physical model. In these experiments, different variables were evaluated through a set of 24 tests to obtain the more relevant parameters affecting the seabed. They concluded that the propeller rotation velocity $(n)$ and the distance to the quay wall $\left(X_{w}\right)$ play an important role in the formation of the scouring hole, being both of them dependent on the manoeuvre characteristics.

In this regard, this paper presents a new composite methodology aiming to predict scouring patterns during the arrival and departure manoeuvres, which combines field and real data with a manoeuvre numerical simulator and tests some of the most commonly used formulas for maximum scouring depth prediction. For the first time, a manoeuvre numerical simulator is used to obtain real variables (e.g. the propeller rotation velocity, the main engines power and the propeller pitch) to compute the maximum scouring depth expected at a particular harbour basin.

\section{Study case}

The study quay is located at the Western Mediterranean Sea. Due to confidentiality agreements with this particular Port Authority, exact location will not be named throughout the document (Mujal-Colilles et al., 2017a). concluded that the most harmful vessels were a combination of ship draft to water column ratio and docking frequencies: regular lines of ships (between 6 and $8 \mathrm{~m}$ draft) with a nearly daily docking frequency at Western Mediterranean harbours, with mean water column depths of 10-14 m. Specifically, Ro-Ro and Ro-Pax ships which tend to use the same dock due to mooring and operational needs, exempted from compulsory pilotage and without tug assistance.

The quay focus of the present research is located at the inner face of a harbour basin, Fig. 1a. This is one of the most used dockings by Ro-Ro ships in the port, being daily used by the study vessel in this article or other ferry ships with similar characteristics. The sediment bed characteristics obtained by the Port Authority in a sampling campaign (2015) using VibroCores and Van Veen dredges yielded a ground profile of a first layer $0.5 \mathrm{~m}$ thick of muddy and sandy sediment, below which there is a gravel layer with $d_{50}=2 \mathrm{~mm}$ and $\rho=2650 \mathrm{~kg} \mathrm{~m}^{-3}$. The quay was designed to have $10-12 \mathrm{~m}$ of depth, however, bathymetric results (Fig. 1b) show how the sediment bed has been eroded up to $17.5 \mathrm{~m}$ below sea level (m.b.s.l). The eroded area is located around the back quay, coinciding with the stern propellers position. Previous studies in other ferry dockings also found that the maximum erosion is generated near the back quay, therefore this study is focused on the main stern propellers' behaviour and their potential scouring effects.

The study vessel is a Ro-Ro type, $199 \mathrm{~m}$ in length, $27 \mathrm{~m}$ in beam and a maximum draft of $6.4 \mathrm{~m}$. The ship is also equipped with two stern propellers having a diameter, $D_{p}=5.1 \mathrm{~m}$, rotating at maximum velocities, $n=130 \mathrm{rpm}$, and connected to an engine of indicated power, $P=$ $13000 \mathrm{~kW}$. This vessel performs short sea shipping routes and have a daily frequency of calls in the same port. As many of the ferry ships in the western Mediterranean ports, the arrival and departure manoeuvres are performed according to a very defined pattern, thus the main trends are repeated daily unless limited by external conditions (e.g. extreme meteorological conditions or misfunction of any of the ship manoeuvring systems). Critical meteorological conditions in the study port in terms of manoeuvring big size ships with big freeboard are NW and SW winds, perpendicular to the study quay. Historical data from the State Meteorological Agency (AEMET) show that NW events are less frequent but more intense, clearly affecting manoeuvres rather than more frequent less intense SW events.

\section{Methodology}

The methodology presented in this contribution combines three different areas: i) field data (Automatic Identification System (AIS) and Acoustic Doppler Velocimetry (ADV) data), ii) manual reproduction of the manoeuvres by means of a manoeuvre numerical simulator and recording of the main parameters involved in the scour during the manoeuvre (speed of rotation of the propellers, $n$, pitch ratio of the propellers, $p$ ', and power output of the main engine, $P$ ), iii) application of pre-existing formulae to compute maximum flow velocity at the seabed and maximum expected scouring depth. Fig. 2 correlates these three different areas with the data obtained from and used for each of them (input and output).

Field campaigns are designed to obtain AIS information from the ship and velocity data of the propeller induced wash using ADV. Wind velocity data during the days of campaign is also obtained to take into consideration the external conditions in case is needed. Finally, the bathymetry of the harbour basin, provided by the Port Authority, is used to validate the results, by comparing the observed erosion (depth and location) with the analytic results obtained through empirical scour models.

AIS data is used to characterise and analyse the manoeuvre patterns 
b)
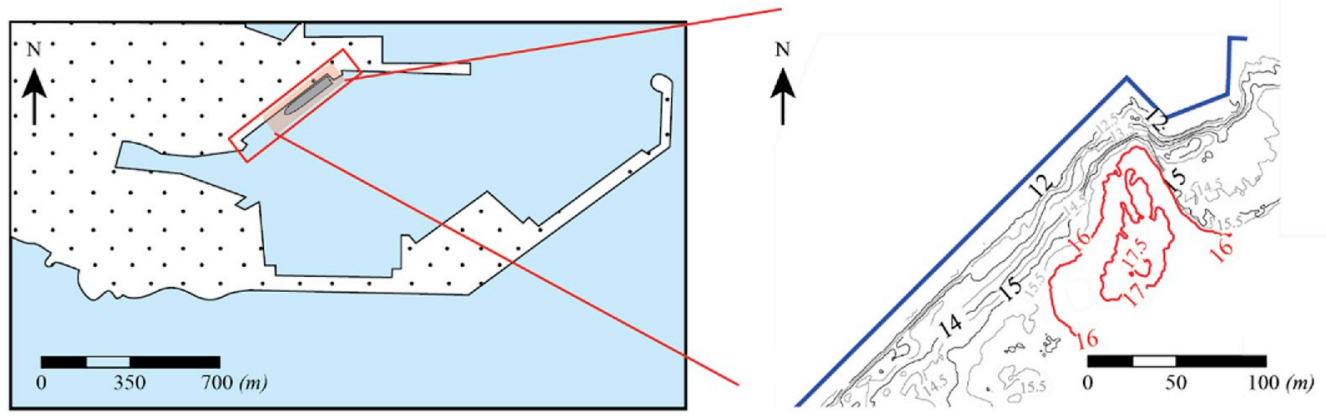

Fig. 1. a) Location of the study quay, red square; b) Zoom in and bathymetry of the docking quay. (For interpretation of the references to colour in this figure legend, the reader is referred to the Web version of this article.)

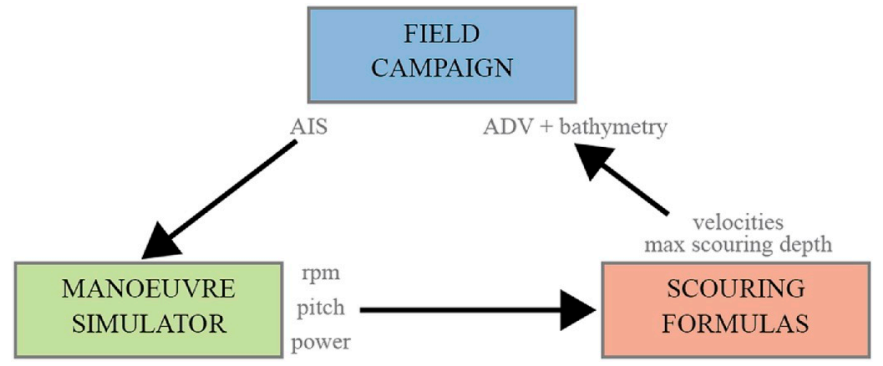

Fig. 2. Data acquisition methodology designed to validate results obtained from scouring formulas with real cases.

and the main parameters obtained are used as a guidance to perform the manoeuvre in the simulator. Time (UTC), Speed Over Ground (SOG), Heading (HDG), Course Over Ground (COG) and position are needed to properly reproduce the manoeuvre in the simulator. When the manoeuvre is reproduced, the simulator yields, among others, the values of the propeller speed of rotation, $n$, pitch ratio, $p$ ', and power of the main engines, $P$, as output. This information is considered to be comparable to what would be obtained from on-board data records of the same parameters. This output is used as input independent variables in the formulas proposed in literature to obtain the efflux velocity, maximum seabed flow velocities and maximum scouring depth during the manoeuvres. To validate the results obtained from the scouring formulas, the bathymetry of the bed sediment of the harbour basin shown in Fig. 1b is used. In the next subsections, each method is described to provide a deeper insight of every one of them.

\subsection{Field campaign}

\subsubsection{In situ measurements of propeller jet velocity}

A two-day field campaign ( 2 arrival and 2 departure manoeuvres) was designed to record flow velocities at a vertical quay wall, synchronized with AIS and meteorological data. Flow velocities were measured using three different Doppler instruments from Nortek, a punctual instrument (ADV, Vector) and two profilers (Aquadopp and Signature). However, the use of the two profilers was discarded due to the high level of turbulence present in the flow and the post processing methods of the profilers, particularly the averaging step in each layer. Therefore, only ADV data will be discussed throughout the document. The ADV was secured to the quay wall using a dry gravity supporting system located parallel to the ship, together with an anchorage system direct to the vertical concrete wall. Specific characteristics of the location of the ADV with respect to the propellers both in plane and vertical view are detailed in Fig. 3a and Fig. 3b, respectively.

$\mathrm{ADV}$ was positioned in relation to the quay wall in order to set the coordinate system with $\mathrm{x}$-axis perpendicular (transversal velocity a)

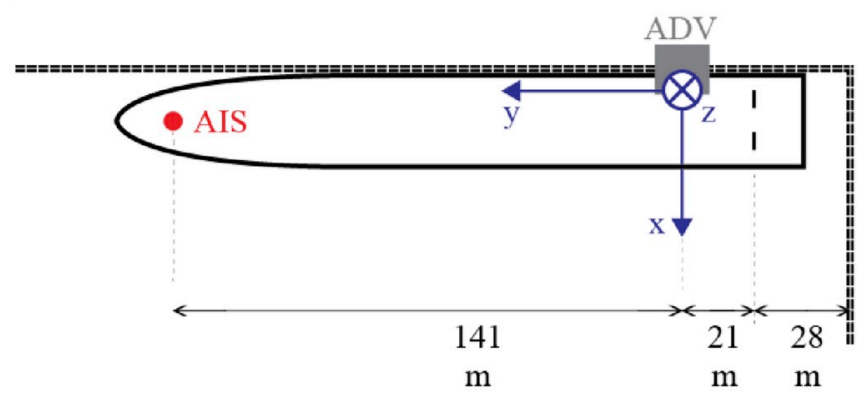

b)

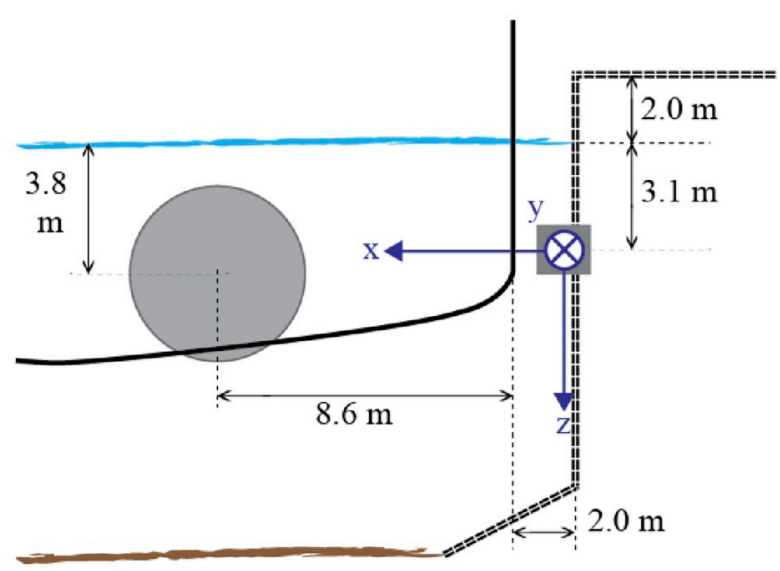

Fig. 3. Sketch of the ADV location with respect to ship and quay. a) Plane view, scale factor 1:4000; b) section view, scale factor 1:400.

component) and y-axis (longitudinal velocity component) parallel to the wall respectively, as shown in Fig. 3. The sampling rate was set to $8 \mathrm{~Hz}$ and data was filtered using a Savitzky-Golay filter, (Savitzky and Golay, 1964).

As it is seen in Fig. 3, the ADV could not be located right behind the ship propeller due to port operational limitations. Since the current meter is located ahead of the propeller, the obtained direct measures are expected to be the main wash generated by the afore-directed flow of the starboard propeller in astern regime. This limitation lead to consider the current velocity measures just as indicators of the existence of propeller jet flow in the harbour basin and its direction in the ADV position. Thus, the magnitude of the measured velocity in the position of the ADV can't be compared directly with the results of the existent analytic formulae for propeller wash velocity, which refers to the wash velocity of a propeller working ahead. The measures allowed, however, to relate the AIS positions of the ship during the manoeuvre with the measured flow velocity and obtain the set of positions in which the vessel is potentially 
harmful for the seabed.

\subsubsection{AIS data}

AIS recorded data, with a sampling frequency $\approx 1.7 \cdot 10^{-2} \mathrm{~Hz}$ (every minute), consisted on ship's position (latitude and longitude), Speed Over Ground (SOG), Heading (HDG), Course Over Ground (COG), Rate of Turn (ROT) and Coordinated Universal Time (UTC) during the field campaign. The data was recorded by the Port Authority and provided to the authors to allow their analysis.

The UTC time was used to trigger AIS data to ADV recordings, thus allowing to obtain the manoeuvre moments in which higher jet velocities generated by the main propellers are reaching the quay surroundings. HDG and geographical positions of the ship are variables needed to understand the vessel manoeuvre patterns. The distance between the propellers and the main walls must be taken into consideration since they contribute to the scouring action in confined scenarios, as discussed in (Hamill et al., 1999; Mujal-Colilles et al., 2018; Wei and Chiew, 2019). Therefore, bearing in mind that the position obtained from the AIS data corresponds to the position of the AIS transponder (which is located at the bow of the vessel as shown in Fig. 3a) these positions must be later corrected by the distance between the transponder and the propellers considering the HDG of the vessel. By this correction, the position (lat, lon) of the propellers is found. The intersection point of the HDG vector and the quay contour is later obtained and finally the distance between the two points is calculated.

\subsubsection{Meteorological data during the campaign}

Since the vessel manoeuvre can be highly influenced by the wind in the harbour during the operations, wind velocity values were obtained from the Spanish Meteorological Agency, showing velocities of less than $3 \mathrm{~m} \mathrm{~s}^{-1}$ during the field campaign at the study location. This wind intensity is considered to have no considerable effects over the ship manoeuvre according to (Molland, 2011).

\subsection{Manoeuvre simulator}

The Barcelona School of Nautical Studies (FNB, UPC) hosts a Transas NTPro 5000-v-5.35 manoeuvre simulator designed to be used for pilot and captain training, in naval engineering and port management. With the help of this simulator, the recorded manoeuvres during the field campaign are reproduced to obtain the specific behaviour of every necessary variable to estimate the scouring action. The harbour, the study ship and the AIS data are inputs known in the simulator. The particular study ship was not available and therefore, a Ro-Ro ship with similar characteristics was used. Table 1 and Table 2 detail the different characteristics of both, the study and simulator ship. The study vessel is slightly larger than the simulator vessel (up to $8 \%$ ) with larger capacity $(\approx 18 \%)$, but these differences do not affect the arrival and departure manoeuvres. The differences of the stern propellers are also small as seen in Table 2.

The manoeuvre is reproduced in the ship simulator, by a simulator pilot, allowing to obtain a detailed output of the ship main behaviour parameters at $1 \mathrm{~Hz}$ sampling rate to analyse them. Some variables are used to validate the manoeuvre with the AIS data, while the others are used as input to the formulae to calculate the flow velocity and the expected scour depth. The simulator output is summarized in the Table 3 :

Table 1

Ship particulars comparison between the study vessel and the ship used in the manoeuvre simulator.

\begin{tabular}{lll}
\hline & Study ship & Simulator ship \\
\hline Gross Tonnage (GT) & 25993 & 21104 \\
Maximum beam (m) & 27 & 25.5 \\
Maximum draft (m) & 6.4 & 6.5 \\
Maximum length (m) & 199 & 182.6 \\
\hline
\end{tabular}

Table 2

Propulsion system characteristics comparison between the study ship and the ship used in the manoeuvre simulator.

\begin{tabular}{lll}
\hline & Study vessel & Simulator vessel \\
\hline Indicated power $(\mathrm{kW})$ & 12775 & 11520 \\
Propeller diameter $(\mathrm{m})$ & 5.1 & 5.0 \\
Blade number & 4 & 4 \\
Number of propellers & 2 (twin- & 2 (twin- \\
& propeller) & propeller) \\
Propeller centroid depth $(\mathrm{m})$ & 3.8 & 4 \\
Propeller Thrust Coefficient $(\mathrm{Ct})$ & $0.2-0.65$ & $0.2-0.65$ \\
Propeller rotation direction & Inward & Inward \\
Maximum engine rotation velocity (rpm) & 500 & 510 \\
Maximum propeller rotation velocity & 137 & 130 \\
$\quad(\mathrm{rpm})$ & &
\end{tabular}

\subsection{Jet velocity characterisation and scour prediction models}

From the simulator output, most of the existing formulae can be applied to find the efflux velocity, the flow velocity at the seabed and the expected scouring depth at any moment of the manoeuvre. This subsection is also divided into three different sub-subsections to better explain the formulae used in every case.

\subsubsection{Efflux velocity}

In order to analytically evaluate the propeller induced velocities at the seabed of a particular harbour basin or the scouring potential, the efflux velocity, $\mathrm{U}_{0}$, is needed. The expressions proposed by (Fuehrer \& Römisch, 1977; Hamill, 1987; PIANC, 2015; Stewart, 1992) are used in this article to obtain the value of the efflux velocity at every time step of the arrival and departure manoeuvre, using the output of the simulator as input for the equations.

An important remark must be done referring to the propeller type. Ferry ships use mostly controllable pitch propellers, meaning that its pitch is changing as much as the speed of rotation during the manoeuvre, according to the required thrust output. The propeller pitch is one of the variables affecting the most to the $\mathrm{C}_{\mathrm{t}}$. A linear relationship between the pitch ratio and the $\mathrm{C}_{\mathrm{t}}\left(C t=0.5 p^{\prime}-0.05\right)$ is used in this article, obtained from the Wageningen B-Series for 4 blades propeller (Bernitsas et al., 1981).

\subsubsection{Flow velocity at the seabed}

Since the ship is in constant movement during the manoeuvre, the generated jet needs to be studied together with the geometry of the study quay (Fig. 1b) and the manoeuvre itself. Two different flow conditions are considered to obtain the seabed induced flow velocity: confined flow and unconfined flow. The confined flow is defined as the jet flow that reaches the quay wall and deflects on it, thus affecting the seabed due to the previous impingement. The unconfined flow is defined as a developing jet flow that reaches the seabed due to its own expansion.

(PIANC, 2015) proposes the German and Dutch method to obtain the maximum flow velocity at the seabed. The expressions in this report are used to obtain the order of magnitude of the flow velocity at the seabed and the position where it is maximum. To find out which equation is needed at every position of the ship during the manoeuvre, it must be

Table 3

Summary of the output obtained from the manoeuvre simulator.

\begin{tabular}{lll}
\hline & Variable & Units \\
\hline AIS manoeuvre validation & Geographical position & Lat, Lon \\
& Heading & Degrees \\
& Speed over ground & Knots \\
& Manoeuvre time & Seconds \\
Input to formulae & Engine Power & $\mathrm{kW}$ \\
& Main propellers pitch ratio & - \\
& Main propellers speed of rotation & $\mathrm{rpm}$ \\
\hline
\end{tabular}


considered than the flow can be confined, due to the proximity of the quay walls, or unconfined. For both conditions, different formulae in (PIANC, 2015) are used.

In order to obtain the situations in which the manoeuvre must be considered as confined or unconfined, the position of the maximum velocity over the seabed is obtained according to (PIANC, 2015) recommendations, which states that $0.12<h p / X m u<0.22$. Also, the ship position and HDG are used to obtain the distance from the propellers to the quay wall, as described in section 3.1.2. If the distance to the quay wall is smaller than the distance to the maximum seabed velocity, the situation is considered to be confined and vice versa.

Both the AIS information and the output of the simulator (geographical coordinates and HDG vector) allow to obtain the axial distance from the ship propellers to the quay wall. However, the information of the AIS is not enough to evaluate the positions in which the vessel turns to be more harmful for the port infrastructure, since the behaviour of the propeller during the manoeuvre is not known. Combining the ship position and HDG during the manoeuvre with the output of the engine and the propeller obtained in the simulator, German and Dutch method (PIANC, 2015) are used to find out the value of the jet velocity at the seabed, yielding also the location in which it is higher and its expected magnitude.

\subsubsection{Maximum expected scouring depth}

Many studies approached the scouring action of a propeller in unconfined situations, however, a lack of formulation is found when trying to evaluate the potential scouring action of main propellers in a confined scenario. Although the confinement is a common topic and some authors and guidelines consider this issue (BAW, 2005; Blokland and Smedes, 1996; Gaythwaite and Drive, 2004; Hamill et al., 1999; Mujal-Colilles et al., 2018; PIANC, 2015), only a few proposed an equation to compute the final scour generated by main propellers in a confined wash condition (Hamill et al., 1999; Hashmi et al., 1992; Ryan et al., 2013; Wei et al., 2018). (PIANC, 2015) proposes a set of equations, extracted from (Römisch and Hering, 2002) to calculate the expected scour generated by confined washes, but according to the guidelines, their use is only recommended for transverse thrusters.

Since this study is focused on the seabed scour near the quay walls due to main propellers action, the scouring potential of the manoeuvre is obtained with the equations proposed by (Hamill et al., 1999). They proposed an equation which considers the erosion depth near a quay wall as an increment respect to the erosion depth that would be expected from an unconfined situation. This equation is proposed for single propellers in absence of ship and rudder, however (Mujal-Colilles et al., 2017a), applied satisfactorily the equation in a study case with high similarities to the one in this article. In that study, the erosive action of a twin propeller ferry due to the arrival and departure manoeuvres was studied through a collection of bathymetries in which the seabed morphology evolution was observed. The equation proposed by (Hamill et al., 1999) fitted the results reasonably well in combination with the expression provided by (Hamill, 1987) for unconfined flow. In this article, both the method in (Hamill et al., 1999) and the combination in (Mujal-Colilles et al., 2017a) are applied to the study case for the ship positions in which confined flow is expected. In this case, the binary output of confinement/unconfinement for every ship position is obtained by calculating the distance to the maximum erosion depth position according to (Hamill et al., 1999) and comparing it with the distance to the quay wall. If the last is smaller, then confinement is expected.

\section{Results}

\subsection{Results of field campaign}

During the field campaign, AIS information and data of the propeller generated wash velocity from ADV measures are simultaneously obtained. The AIS recorded positions are shown in Fig. 4 (right panels), along with the mapped quay contour, recalling that the plotted position is the exact location of the AIS transmitter position in the vessel. To compare the ship behaviour main characteristics during the manoeuvre, the AIS system allows to obtain not only the position, but also SOG and HDG information. Thus, time series of every variable are used to analyse the manoeuvre. Fig. 4 (left and central panels) shows SOG and HDG evolution during the arrival and departure manoeuvres. Correlation coefficients between HDG and SOG data of different days are obtained, yielding $\mathrm{R}^{2}>0.98$ in all cases, which means high similarity between manoeuvre 1 and 2 both in the arrival and the departure manoeuvres.

Because of limitations on the data acquisition, HDG values are not obtained during the Arrival 1 manoeuvre, Fig. 1a (central panel). However, due to the high correlation index in SOG variable and the ship track coincidence between Arrival 1 and Arrival 2, high HDG correlation is assumed.

Fig. 5 compares the ADV recorded wash velocity data obtained during the field campaign (left panels) and the heading vectors of the vessel (right panels) obtained from the AIS information data and triggered according the UTC time of the ADV measures. The framed time slot corresponds to significant propeller generated wash velocity measures. In general terms, ADV measures in Fig. 5 show higher velocities parallel to the side quay (longitudinal component, $U_{y}$ ) and towards the seabed (vertical component, $U_{z}$ ). Velocities perpendicular to the side quay (transversal component, $U_{x}$ ) can be neglected, since they are one order of magnitude smaller compared to longitudinal and vertical components.

During the Arrival 2, Fig. 5a, maximum velocities are close to $0.5 \mathrm{~m}$ $\mathrm{s}^{-1}$, both positive and negative, parallel to the starboard docking wall. Since the sign of the signal changes during the ship's approach to the dock, a more complex combination of engine orders is expected during this manoeuvre in comparison with a simpler usage of the main engines and propellers during the departure manoeuvre, combining ahead and astern rotation as per the needs of the manoeuvring ship in order to ensure a fast and safe approach to the berth. This combination of astern and ahead regime during the arrival manoeuvre will be obtained and analysed with the output of the simulator, once the manoeuvre is reproduced (section 4.2 ).

The field measures during the departure manoeuvres, Fig. 5b,
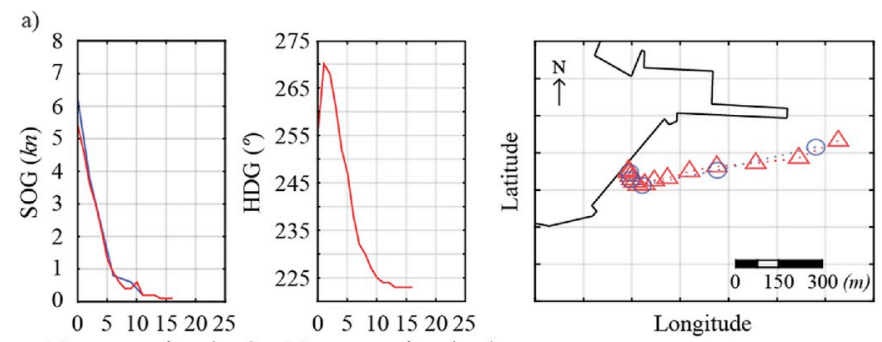

Manoeuvre time $(\mathrm{min})$

Manoeuvre time $(\mathrm{min})$

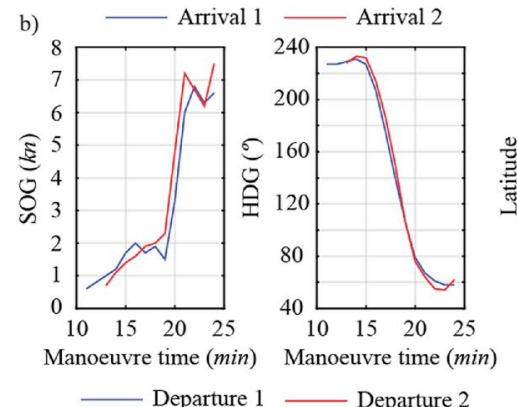

○. Arrival $1 \cdots \Delta \cdots$ Arrival 2

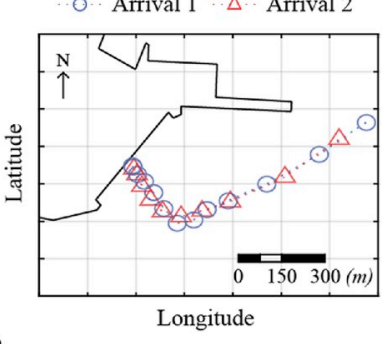

•๑ $\cdot$ Departure $1 \cdots \Delta \cdot \cdot$ Departure 2

Fig. 4. Manoeuvre characteristics time series (left and central panels) and AIS mapped positions (right panels) for the (a) arrival and the (b) departure manoeuvres. 
a)
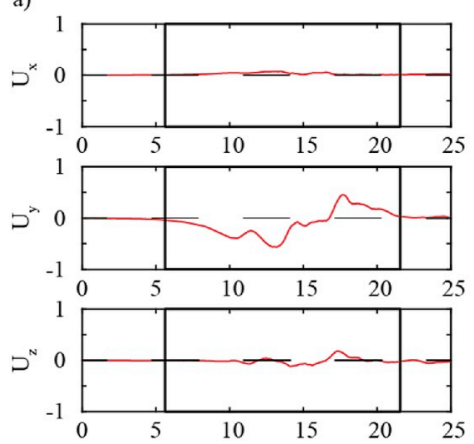

b)
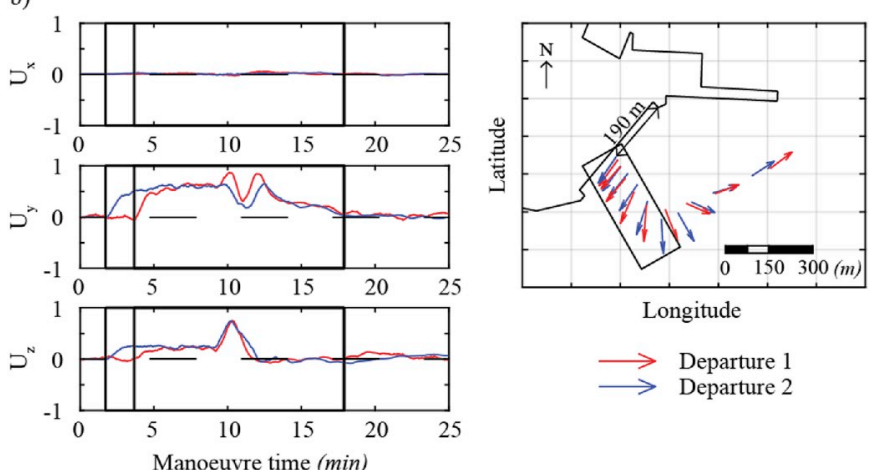

Longitude

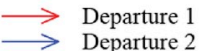

Fig. 5. Propeller wash velocity $\left(m \cdot s^{-1}\right)$ (left) and mapped HDG vectors (right) during the a) arrival and b) departure manoeuvres. Framed sections on the time series correspond to the framed areas on the map.

yielded maximum bow-directed velocities of $0.5-1 \mathrm{~m} \mathrm{~s}^{-1}$ between minutes 10 and 13, corresponding to the first phase of the ship's movement when linked to the AIS records shown in Fig. 4b. Before that minute, although the propellers are already working, the ship is almost motionless. Correlation coefficients between Departure 1 and 2 are 0.8 and 0.84 for longitudinal $\left(U_{y}\right)$ and vertical $\left(U_{z}\right)$ signals respectively, bearing in mind that Departure 1 signal is delayed by 2 min with respect to the signal 1. Correlation coefficients of 0.92 and 0.90 for longitudinal and vertical signals are obtained if the manoeuvre is considered to begin at minute 5 . Remarkably, although the area covered by the set of positions framed in Fig. 5 (right panels) is wider at the departure manoeuvres, the time-slot of ADV measures is similar for all the manoeuvres (15-18 min), meaning similar duration of the scouring forcing action at any manoeuvre.

\subsection{Results of manoeuvre simulator}

The AIS data analysis is used to reproduce the study case manoeuvres in the manoeuvre simulator. SOG and HDG time series obtained from the manoeuvre simulator, along with mappings of the HDG vectors at the AIS positions (green lines), are compared to real manoeuvres (blue and red lines) in Fig. 6. Framed areas previously showed in Fig. 5 are also shown in Fig. 6 (right panels), this time by shadowing the area in green.

Correlation coefficients of SOG and HDG time series obtained from the manoeuvre simulator and real data from AIS (Fig. 6, left and central panels) were $\mathrm{R}^{2}>0.94$ in all cases and confirming that the manoeuvre is well reproduced in the simulator. The HDG vector mapping, is also used to visually compare the ship behaviour during the simulated and real manoeuvres (Fig. 6, right panels). Although little differences can be observed in the time series and the vector mappings, these are considered to be acceptable deeming the change of the ship characteristics and the ship operator.

After reproducing the manoeuvre, the manoeuvre simulator yields the needed variables to apply the flow velocity and scouring prediction
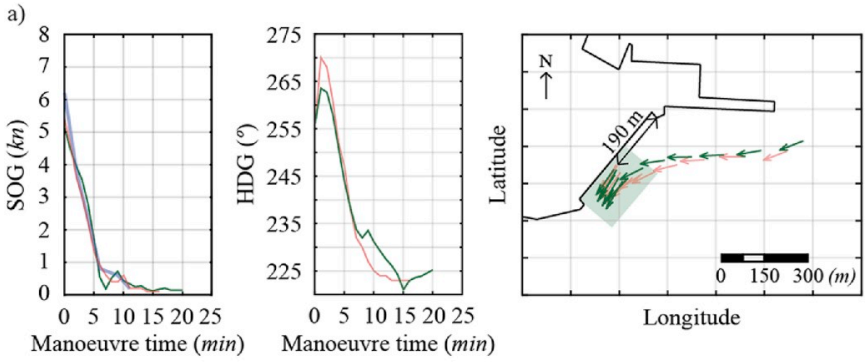

Manoeuvre time (min)
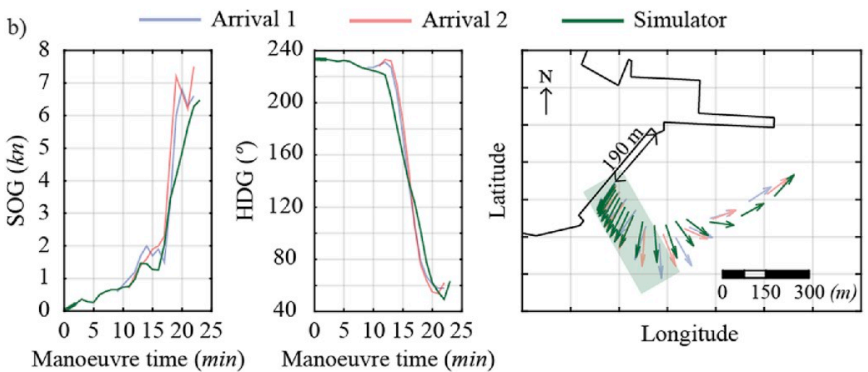

- Departure $1 \longrightarrow$ Departure $2 \longrightarrow$ Simulator

Fig. 6. Manoeuvre characteristics time series (left and central panels) and mapped HDG vectors (right panels) during the a) arrival and the b) departure manoeuvres. Green shadowed areas refer to the framed areas in Fig. 5. (For interpretation of the references to colour in this figure legend, the reader is referred to the Web version of this article.)

equations existing in literature: main engine power, $P$, the propellers speed of rotation, $n$, and the propeller's pitch ratio, $p^{\prime}$. Fig. 7 shows the evolution of the mentioned variables during both the arrival (Fig. 7a) and the departure (Fig. 7b) manoeuvre. The green shadowed time slots correspond to the green shadowed areas in Fig. 6 (right panels), which refer to the time slot in which significant wash velocities were measured during the field campaign (Fig. 5, left panels). Figs. 6 and 7 describe the ship and the propulsion system behaviour during the manoeuvre, so the characteristics of the manoeuvre are linked to the propeller and engine variables behaviour.

In the arrival manoeuvre, during the first $7 \mathrm{~min}$ the ship is

a)
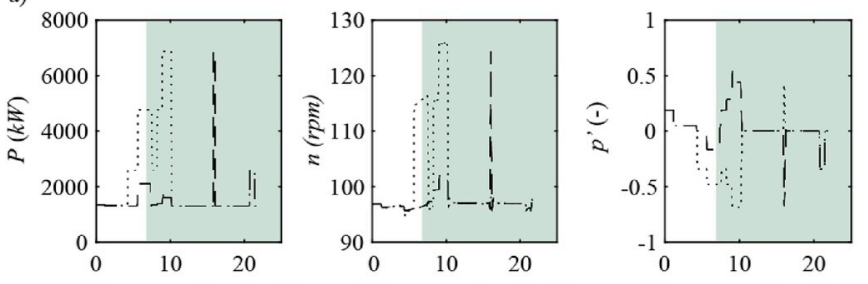

b)
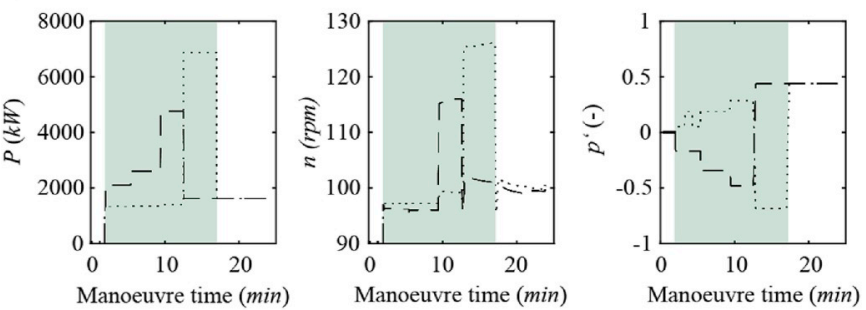

- Starboard engine/propeller ... Port engine / propeller

Fig. 7. Time series of the propeller related variables during the manoeuvres performed at the manoeuvre simulator. Green shadowed areas correspond to the significant ADV measures obtained at field. a) Arrival manoeuvre; b) Departure manoeuvre. (For interpretation of the references to colour in this figure legend, the reader is referred to the Web version of this article.) 
approaching the quay (Fig. 6a), first turning to the starboard until HDG $\approx 270^{\circ}$, then turning to the port until HDG $\approx 230^{\circ}$. At this time (minute 7) SOG is below $1 \mathrm{kn}$. To begin the lateral movement towards the side quay, the starboard propeller regime is changed ahead, while the port propeller is turned astern generating a torque movement, Fig. 7a (right panel). The bow thruster is used during the final approach to compensate this torque movement and permitting the ship to move in parallel to the quay wall. The inertia drives the ship to the side quay and finally the propeller regimes are inverted (starboard propeller: astern; port propeller: ahead; bow thruster: out) to stop the inertial movement.

The departure manoeuvre analysis shows a simpler scheme to reproduce the manoeuvre. The first $12 \mathrm{~min}$ consist on lateral displacement (Fig. 6b), with the starboard propeller running astern and the port propeller running ahead at low regime for $8 \mathrm{~min}$ and mid regime from minutes 8 to 12 (Fig. 7b). During this time, the bow thruster is used intermittently to maintain constant heading compensating the generated torque. After the minute 12, the propeller regime is reverted, see Fig. $7 \mathrm{~b}$, and the turning manoeuvre begins, turning the ship to the port side describing a circular trajectory, from $\mathrm{HDG} \approx 225^{\circ}$ to $\mathrm{HDG} \approx 65^{\circ}$, as shown in Fig. 6b. After that, both propellers run ahead in parallel and the ship departs the port.

\subsection{Jet velocity characterisation and scour prediction models}

Once the manoeuvres are well reproduced and the main propeller and propulsion system variables are obtained, the scouring potential of each case is studied by means of formulation widely used in civil engineering. The next subsections show the obtained results of applying that formulae to a real manoeuvre output, as the obtained from the simulator.

\subsubsection{Efflux velocity}

The scouring action of a propeller jet is considered a function of the efflux velocity, $U_{0}$, among other variables (propeller diameter, quay geometry, sediment size). Thus, $U_{0}$ is calculated according to different methods, to further compare the results in the current study case (Fuehrer \& Römisch, 1977; Hamill, 1987): propose $U_{0}=f\left(n, D_{p}, C_{t}\right)$ with two different coefficients (1.59 and 1.33 respectively) (Stewart, 1992); considers $U_{0}=f\left(n, p^{\prime}, D_{p}, C_{t} \beta\right)$ and (PIANC, 2015) recommends $U_{0}=f$ $\left(P, \rho_{w}, D_{p}\right)$. Fig. 8 show the results obtained for $U_{0}$ depending on the method for every manoeuvre.

Efflux velocities obtained with (Stewart, 1992) formulation, in Fig. 8, show considerable differences compared to the others due to the low pitch ratio ( $p$ ') of the vessel when manoeuvring inside the harbour basin. The following calculations, thus, do not include these results as they are considered to underestimate the propeller induced flow velocity.

\subsubsection{Flow velocity at the seabed}

The propeller jet flow reaches the seabed at changing locations during the manoeuvre due to the vessel movement. Where is the jet actually reaching the seabed has been a matter of study in the recent years. For free propeller jets (Hamill et al., 1999), proposed an equation to calculate the axial distance from the propeller to the maximum eroded depth for unconfined situations $\left(X_{m u}=f\left(F_{0}, c\right)\right.$ ). Recently (Tan and Yüksel, 2018), modified the equation to better fit a wider range of sediment diameters and proposed a new equation $\left(X_{m u}=f\left(F_{0}, h_{p}, D_{p}\right)\right)$. According to (PIANC, 2015), the experiments of (Verhey, 1983) confirmed that the maximum velocity at the seabed is expected at 0.12 $<h_{p} / X_{m u}<0.22$, meaning distances between 70 and 40 m downstream the propellers for the study case in this article. In confined situations, however, the maximum jet velocities at the seabed are expected right below the confinement structure (i.e. quay wall, open quay, pile, etc.).

To obtain an approximated value of the magnitude of the seabed induced velocities, Dutch and German methods for confined $\left(U_{b}=f\left(U_{0}\right.\right.$, $\left.\left.h_{p}, D_{p}, L\right)\right)$ and unconfined $\left(U_{b}=f\left(U_{0}, h_{p}, D_{p}\right)\right)$ situations are applied. Fig. 9 shows the AIS positions and the maximum seabed velocity a)

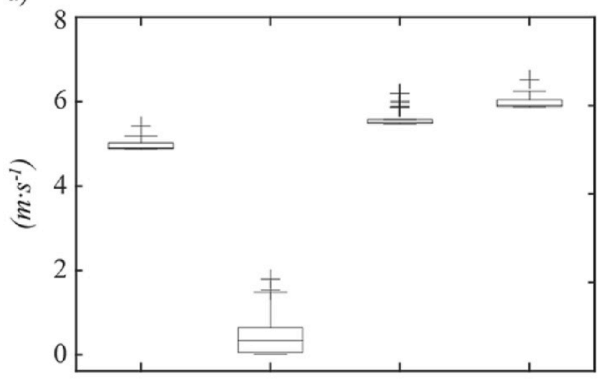

(i) (ii) (iii) (iv)

b)

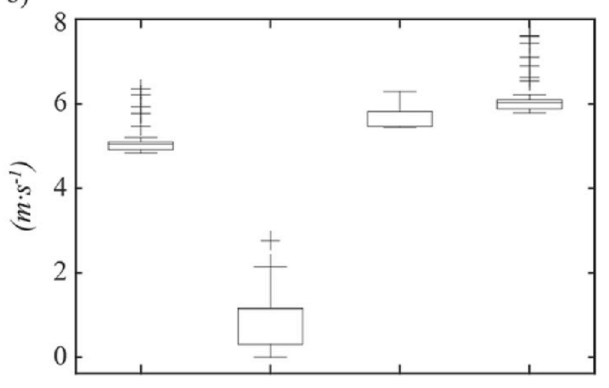

(i) (ii) (iii) (iv)

Fig. 8. Boxplots of non-zero efflux velocities during the a) arrival and b) departure manoeuvre according the equations in (i) (Hamill, 1987) (ii) (Stewart, 1992) (iii) (PIANC, 2015) (iv) (Fuehrer, M., \& Römisch, 1977).

locations according to the (PIANC, 2015) formulation. The confinement or unconfinement criteria is obtained by applying a threshold according to the recommendations in the guidelines $\left(h_{p} / X_{m u}=0.2\right)$. The main differences arise when comparing Dutch and German method for unconfined flow, which are represented by the coloured points away from the quay. Along the quay wall (corresponding to the confined situation) the obtained velocities are very similar for both methods in arrival and departure manoeuvre.

\subsubsection{Maximum expected scouring depth}

In the present study case (Hamill et al., 1999), and the combination
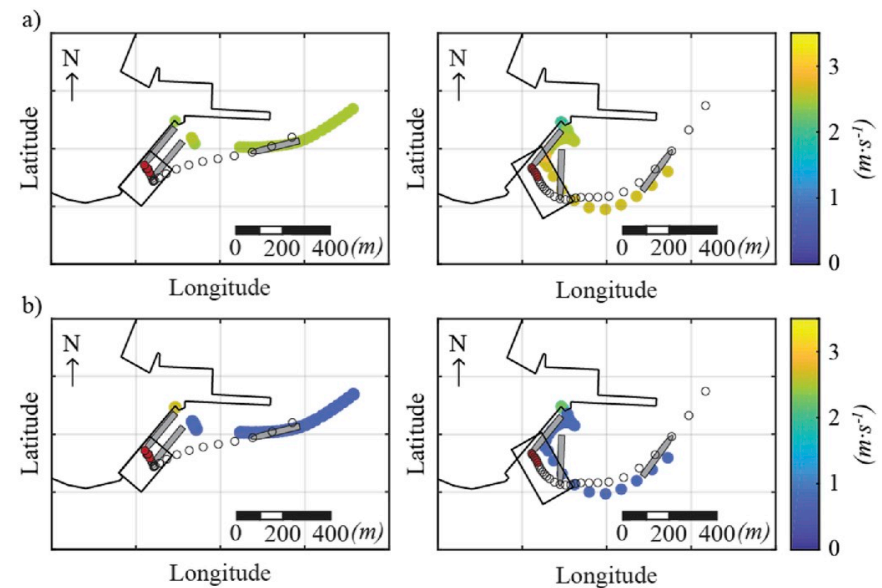

Fig. 9. Maximum seabed velocity magnitude and location during the arrival (left) and departure (right) manoeuvre. a) Dutch method; b) German method. AIS data is shown with empty or red filled circles. The red filled markers show the set of positions in which a confined flow situation is expected. The AIS positions are framed according to the framed section in Fig. 5. (For interpretation of the references to colour in this figure legend, the reader is referred to the Web version of this article.) 
in (Mujal-Colilles et al., 2017a) are used to obtain maximum scouring depths and the set of ship positions in which the higher damage is caused. The position in which the erosion is plotted has been obtained with the intersection between the HDG vector of the ship and the quay wall, but only for the positions in which confinement is expected according to the formulae in (Hamill et al., 1999).

To compute the scour in confined situations, the equations proposed in (Hamill et al., 1999) considers the its maximum depth as $\varepsilon_{m}^{c}=f\left(F_{0}\right.$, $\left.D_{p}, c, d_{50}, X_{w}, X_{m u}\right)$. Constraints of the mentioned methods and the present study case are summarized in Table 4.

Results of the expected scour are mapped in Fig. 10, linked to the ship manoeuvre. The coloured sections show the maximum expected eroded depth at the quay wall. The AIS positions (at the bow of the ship) are indicated using empty circles, filled in red when flow confinement is expected. The obtained values showing the eroded depth are in range of the expected, being of the same order of magnitude as the obtained eroded depth from the bathymetry. Both combinations, moreover, yielded similar results, also in agreement with the location of maximum expected seabed velocities near the quay wall, obtained in the previous section with a different method.

\section{Discussion}

The jet flow generated by manoeuvring ships nearby vertical structures is known to erode the seabed sediment but is still difficult to predict the effects of a particular ship operating in a harbour basin. Surprisingly, the study of the erosion generated by ship's propeller has barely been related with the manoeuvre itself, which is the main causative of the propeller's behaviour.

(BAW, 2010) discuss the effects of the potential damage of the propellers and provide guidelines to design the protections taking into account their action. The physical characteristics of the propeller are used, along with the rotation rate and the power of the engine as the main indicators of this potential damage, and thus, as the main parameters to consider when designing the protection. The mooring (final stages of the arrival manoeuvre), the cast off (the beginning of the departure manoeuvre) and the acceleration phase (when the ship is sailing out of a quay) are considered the situations in which the vessel, manoeuvring at low speed, uses maximum propeller power and therefore is potentially more harmful for the seabed. Mooring and cast off are both the situations found to generate higher damage to the seabed, according to the results shown in this article.

This work presented a methodology to take the ship manoeuvre into consideration as the main causative of the sediment scour. The intention of this contribution is the validation of the manoeuvre simulation through field data in order to obtain the main parameters involved in the scouring action during two particular manoeuvres (arrival and departure). Therefore, one of the objectives of this work is to allow similar simulator studies to be used in further research to improve the ship manoeuvres to prevent consequences over the port structures, seabed and operability.

ADV data are used to characterise the propellers jet flow direction on the quay surroundings and to obtain the duration of the erosive forcing at every manoeuvre. The position where the ADV is located (forward to the propellers and near the side quay wall) clearly conditioned the

Table 4

Constraints of the proposed formulation and the study case.

\begin{tabular}{|c|c|c|c|c|c|c|}
\hline & $F_{0}$ & $\frac{X_{w}}{h_{p}}$ & $\frac{X_{w}}{X_{m}^{u}}$ & $\frac{d_{50}}{D_{p}}$ & $\frac{h_{p}}{D_{p}}$ & $\frac{X_{w}}{D_{p}}$ \\
\hline Study Case & $\begin{array}{l}40- \\
80\end{array}$ & $>3$ & $0.14-0.5$ & $4 \cdot 10^{-4}$ & 1.6 & $>7$ \\
\hline $\begin{array}{l}\text { Mujal-Colilles et al. } \\
\text { (2017a) }\end{array}$ & $\begin{array}{l}35- \\
170\end{array}$ & - & - & $10^{-4}$ & 1.3 & - \\
\hline Hamill et al. (1999) & $5-18$ & - & $0.636-2.7$ & $\begin{array}{l}5 \cdot 10^{-3}- \\
5 \cdot 10^{-2}\end{array}$ & $1-3$ & - \\
\hline
\end{tabular}
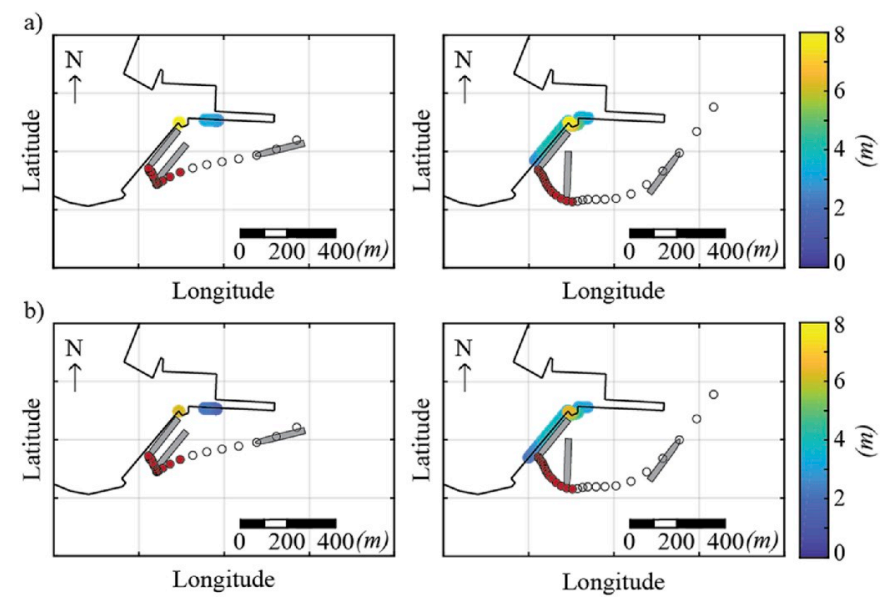

Fig. 10. Erosion generated by main propellers during the arrival (left) and the departure (right) manoeuvre. Coloured areas show the location of the maximum eroded depth, over the quay wall, during the manoeuvres. The ship contour is mapped according to the manoeuvre characteristics at different AIS positions (red and empty circles). Red circles indicate the ship position in which a confinement situation is found. Erosion values are obtained according to the formulation in: a) (Hamill et al., 1999); b) (Mujal-Colilles et al., 2017a). (For interpretation of the references to colour in this figure legend, the reader is referred to the Web version of this article.)

measured values, which cannot be compared with the results of the equations in literature, mostly addressed to obtain the maximum axial velocity of the jet flow behind the propeller plane. The direction of the jet (Fig. 5 left, longitudinal component), however, gives information about the behaviour of the propellers during the manoeuvre, and it can be compared to the pitch sign obtained from the manoeuvre simulator (Fig. 7, right panels). Besides, the time slot in which significant velocities are measured (Fig. 5 left, framed area) is used to validate the propeller behaviour near the side quay (Fig. 7, green area). Both flow direction and time duration are coherent according to the ADV measures and the simulator output. The AIS data are satisfactorily used to link the ship position with the mentioned ADV measures.

The velocity measures obtained at the departure manoeuvre show a constant flow towards the bow and the seabed (positive longitudinal and vertical velocity components), as shown in Fig. 5b, left panels, corresponding to the astern regime of the starboard propeller (the closest to the ADV) during that manoeuvre, as in Fig. 7b. Seafloor directed fluxes are consistent with the experimental results obtained by (Mujal-Colilles et al., 2017b) at $5 D_{p}$, similar than the distance from the propeller to the $\operatorname{ADV}\left(\approx 4 D_{p}\right)$.

From the AIS information (Figs. 4 and 5, right panels), the manoeuvre of the ship is obtained. Since the vessel moves parallel to the quay during the first $13 \mathrm{~min}$ of the manoeuvre, the port propeller behaviour is needed to be working ahead to generate torque in combination with the starboard propeller. Fig. $7 \mathrm{~b}$ shows the output of the pitch variable from the simulator according to this description.

The measures obtained during the arrival manoeuvre show a different behaviour, with astern directed flow (longitudinal component $<0$ ) during the first $7 \mathrm{~min}$ and bow directed flow (longitudinal component $>0$ ) until the end of the manoeuvre (Fig. 5b, left panels). The AIS data in Fig. 5b (right panel) show the ship positions and HDG linked to the ADV. It is remarkable that the first relevant ADV measure is obtained with the ship already in parallel position to the side quay. As shown in Fig. 7a, right panel, the starboard propeller runs ahead $\left(p^{\prime}>0\right)$ when the ADV measures are negative. At the same time, the port propeller works astern $\left(p^{\prime}<0\right)$ to generate torque and the bow thruster acts inwards to maintain a constant heading. At the end of the manoeuvre, the propeller's regimes are inverted to stop the inertia, and the starboard propeller pitch (Fig. 7a, right panel) turns negative, coinciding with the 
positive ADV measures in Fig. 5a, right panel (longitudinal component).

The AIS data yield very useful information of the ship manoeuvre patterns. Data provided by the AIS transmitter have been used the last decade to monitor ships around the world for multiple purposes (Aarsæther, 2011; Aarsæther and Moan, 2009; Castells et al., 2018, 2017; Kim et al., 2012; Silveira et al., 2013). AIS data used in this article is sampled at 1-min rate, a reasonable frequency to monitor the manoeuvre, since the changes of every variable are supposed to be gradual to perform a smooth manoeuvre, thus no abrupt changes are expected between two consecutive records. Ship's HDG and SOG are considered the most useful variables to obtain the ship behaviour during the manoeuvre, along with the ship position.

The obtained values of efflux velocity show considerable differences between (Fuehrer \& Römisch, 1977; Hamill, 1987) and (Stewart, 1992), although all the equations are derived from the axial momentum theory. The main difference is the inclusion of the pitch by (Stewart, 1992), highly conditioning the value of the coefficient in the expression at low pitch ratios. The experiments in (Stewart, 1992) were based on two propellers of $p^{\prime}=1$, far from the pitch ratio range obtained in the manoeuvres in this article $\left(p^{\prime}<0.6\right)$, thus efflux velocity values obtained by (Stewart, 1992) equation are expected to underestimate the output axial flow velocity.

To obtain $U_{0}$ according to (PIANC, 2015), a factor of 0.15 is recommended to be applied to the maximum power of the engine $\left(P_{\max }\right)$, which is considered the regime at which the engine is operating inside the port. As per the simulator output, any of the engines working ahead during the manoeuvre develop $\mathrm{P}>0.15 \cdot P_{\max }$, thus confirming the (PIANC, 2015) threshold. (Puertos del Estado, 2012), however, recommends to apply a factor of 0.4 to the maximum engine power, probably leading to overestimated efflux velocities in some cases.

The obtained values of maximum seabed induced velocity near the quay wall show coherence regardless of the applied method (Dutch method or German method), as in Fig. 9. Some differences arise when comparing the magnitude of seabed induced velocity in the unconfined situation. According to the guidelines, however, German method for unconfined flow is actually expected to overestimate the seabed velocities for the present keel ratios.

Remarkably, the obtained location of maximum seabed velocity show agreement with the area of erosion in the bathymetry, however, several hydrographic surveys are needed to study the evolution of the seabed and to validate the results of the formulae. Considering maximum seabed induced velocity values of $2-4 \mathrm{~m} \mathrm{~s}^{-1}$ and according to (BAW, 2005), the needed $d_{50}$ of the protection rocks is $\sim 1 \mathrm{~m}$ or greater if $\rho_{s}$ of $2500 \mathrm{~kg} \mathrm{~m}^{-3}$ is used, a diameter which is often impractical and can lead to major cost increases.

Two different sets of equations (Hamill et al., 1999; Mujal-Colilles et al., 2017a) are used to obtain the maximum scouring depth expected on the surroundings of the study quay. The criteria to consider the confinement is obtained according to the formulae in (Hamill et al., 1999). The obtained positions in which confinement is found with this formulae differs substantially than the set of positions found by the recommendations in (PIANC, 2015), which yielded always a smaller value of distance to the maximum seabed velocity, and thus a smaller range of positions considered to generate erode the seabed due to the confinement situation.

Although the formulae are satisfactorily applied, the time scale in which the expected erosion is reached remains unknown. Actually, the formulation is based on the idea of a stationary flow reaching the seabed, until some equilibrium condition is found. This ideal condition is not expected in real cases due to the arrival/departure manoeuvre iteration and the ship movement, so the obtained values of maximum expected erosion are used as approximations to the real case. Moreover, the effects of the astern/ahead rotation are not taken into consideration, but they obviously play an important role in the real case of a manoeuvring ship, as it is explained in this article when the manoeuvre is analysed and reproduced (section 4.2). (Mujal-Colilles et al., 2018) showed how the combination of forward/backward flow change the seabed morphology evolution when compared to the effects of a stationary forward flow.

Potentially affected areas are also identified with the obtained results, showing a larger damaged area during the departure manoeuvre than during the arrival one. The sections with higher eroded depth, though, coincides in both the arrival and departure manoeuvre analysis at the back quay of the Ro-Ro ship, in agreement with the international guidelines advise (BAW, 2005; PIANC, 2015). At this point, the percentage of used power is one of the highest of all the manoeuvre, and equally important, the distance to the back quay is reduced to its minimum.

\section{Conclusions}

A new approach to study the propeller generated potential scouring is hereby presented. The manoeuvre characteristics are the main factor to estimate the seabed scour near quay walls. From the real manoeuvres, analysed through AIS data, the manoeuvre patterns are identified to be later reproduced at the manoeuvre simulator. The simulator output provides detailed information of the ship propeller's behaviour during the manoeuvre. Therefore, important propeller and main engine related variables ( $n, p^{\prime}$ and $P$ ), which otherwise would be unknown, are obtained.

The results from the manoeuvre simulator, when linked to the recommendations in the international guidelines such as (PIANC, 2015), turned to be very useful to properly find the areas of the seabed where higher flow velocity must be expected. Thus, the obtained results are considered to be helpful to a proper port management in regard of the seabed erosion. New simulator studies should be done to evaluate the effects of the changing meteorological conditions to find out thresholds from which the vessel, due to heavy wind conditions, needs a propulsion power that is too high to ensure no damage to the seabed and to the port infrastructures. The simulator is also a worth tool to perform this kind of studies.

Formulation in literature have been used to obtain quantitative results of the potential scouring action, even knowing that the formulae come from experimental studies and scaling effect due to the noncohesive sediment size limitations must be expected. However, the used combination of formulae in the article showed realistic results in terms of maximum expected scouring deph, in the same order of magnitude than the provided bathymetry.

The main limitations of the presented methodology are related to the applicability of the empirical scour models to the complex reality of a manoeuvring vessel. However, the presented method to link AIS and simulator studies allow to locate the areas of interest, leading to the possibility of testing new manoeuvres and to study the reduction of the damage. It is considered that a faithful reproduction of the manoeuvres with the simulator allow to detect the points of main interest and also the areas in which no effects from the propellers jet should be expected.

\section{Author contributions}

Toni Llull: Conceptualization, Methodology, Investigation, Software, Validation, Writing - Original Draft, Writing - Review \& Editing. Anna Mujal-Colilles: Conceptualitzation, Methodology, Investigation, Writing- Original Draft, Supervision.

Marcel-la Castells: Conceptualitzation, Resources, Supervision, Project administration, Funding acquisition.

Xavier Gironella: Conceptualitzation, Resources, Supervision, Project administration, Funding acquisition.

\section{Funding}

This work has been supported by MINECO (Ministerio de Economía y Competitividad) and FEDER (Unión Europea- Fondo Europeo de 
Desarrollo Regional "Una Manera de hacer Europa") from Spanish Government through project TRA2015-70473-R.

\section{Declaration of competing interest}

The authors declare that they have no known competing financial interests or personal relationships that could have appeared to influence the work reported in this paper.

\section{Acknowledgements}

We greatly acknowledge the technical staff of the UPC CIEMLAB for their support throughout the field campaign: Joaquim Sospedra, Jordi Cateura and Òscar Galego.

\section{Notation}

$\beta \quad$ blade area ratio $(-)$

$c \quad$ propeller tip to bed clearance distance (m)

$C_{t} \quad$ propeller thrust coefficient (-)

$D_{p} \quad$ propeller diameter $(\mathrm{m})$

$d_{50} \quad$ mean sediment size $(\mathrm{m})$

$\varepsilon_{m}^{c} \quad$ maximum scour depth due to confined flow (m)

$F_{0} \quad$ densimetric Froude number (-)

$n \quad$ propeller rotation velocity (rpm)

p' $\quad$ propeller's pitch ratio (-)

$P \quad$ main engine power (W)

$\rho_{s} \quad$ sediment density $\left(\mathrm{kg} \cdot \mathrm{m}^{-3}\right)$

$\rho_{w} \quad$ water density $\left(\mathrm{kg} \cdot \mathrm{m}^{-3}\right)$

$U_{0} \quad$ efflux velocity $\left(\mathrm{m} \cdot \mathrm{s}^{-1}\right)$

$U_{\text {seabed }} \quad$ maximum flow velocity at seabed $\left(\mathrm{m} \cdot \mathrm{s}^{-1}\right)$

$X_{m u} \quad$ distance to the maximum eroded depth in unconfined situation (m)

$X_{w} \quad$ distance between the propellers and the back quay (m)

SOG Velocity of the ship obtained from the AIS transponder between two consecutive transmissions (knots)

HDG Angle between the symmetry line of the ship and the geographic North measured clockwise (degrees)

COG Effective course of the ship between two consecutive transmissions (degrees)

ROT Rate of turn of the ship

\section{References}

Aarsæther, K.G., 2011. Modeling and Analysis of Ship Traffic by Observation and Numerical Simulation. PhD thesis, 2011. Nor. Univ. Sci. Technol. Dep. Mar. Technol. Aarsæther, K.G., Moan, T., 2009. Estimating navigation patterns from AIS. J. Navig. 62 , 587-607. https://doi.org/10.1017/S0373463309990129.

Albertson, M.L., Dai, Y.B., Jensen, R.A., 1950. Diffusion of submerged jets. Trans. Am. Soc. Civ. Eng. 115, 639-664.

BAW, 2010. Code of Practice Principles for the Design of Bank and Bottom Protection for Inland Waterways (GBB).

BAW, 2005. Principles for the design of bank and bottom protection for inland waterways. Bull. No. 88 Fed. Waterw. Eng. Res. Inst. (Bundesanstalt für Wasserbau) 153.

Becker, A.H., Acciaro, M., Asariotis, R., Cabrera, E., Cretegny, L., Crist, P., Esteban, M., Mather, A., Messner, S., Naruse, S., Ng, A.K.Y., Rahmstorf, S., Savonis, M., Song, D., Stenek, V., Velegrakis, A.F., 2013. A note on climate change adaptation for seaports: a challenge for global ports, a challenge for global society. Clim. Change 120 , 683-695. https://doi.org/10.1007/s10584-013-0843-z.

Bernitsas, M.M., Ray, D., Kinley, P., 1981. Kt, Kq and Efficiency Curves for the Wageningen B-Series Propellers. Univ, Michigan.

Blaauw, H.G., van de Kaa, E.J., 1978. Erosion of bottom and sloping banks caused by the screw race of manoeuvring ships. In: Publication N. 202. 7th Int. Harb. Congr. Antwerp, Belgium 202.

Blokland, T., Smedes, R.H., 1996. In situ tests of current velocities and stone movements caused by a propeller jet against a vertical quay wall. In: Proc. 11th Int. Harb. Congr. Antwerp. Belgium.

Castells, M., Martínez De Osés, F.X., Martín, A., Mujal-Colilles, A., Gironella, X., 2017. Tools for evaluation quay toe scouring induced by vessel propellers in harbour basins during the docking and undocking manoeuvring. Mar. Navig. Saf. Sea Transp. $61-66$.

Castells, M., Mujal-Colilles, A., Llull, T., Gironella, F.X., Martínez de Osés, F.X., Martín, A., Sanchez-Arcilla, A., 2018. Ship maneuvre patterns to prevent propeller scouring effects. In: 34th PIANC World Congress, Panama 2018 May 7 to 11: Connecting Maritime Hubs Globally: Book of Abstracts (Pp. 238-1). World Association for Waterborne Transport Infrastructure (PIANC).

Cui, Y., Lam, W.H., Zhang, T., Sun, C., Hamill, G., 2019. Scour induced by single and twin propeller jets. Water 11, 1-20. https://doi.org/10.3390/w11051097.

Ebbesmeyer, C.C., Francisco, M.D., Boatman, C.D., Norton, D., Michelsen, T., 1995. Currents generated by vessel traffic along Seattle's waterfront. In: "Challenges of Our Changing Global Environment". Conference Proceedings. OCEANS '95 MTS/IEEE. IEEE, pp. 26-41. https://doi.org/10.1109/OCEANS.1995.526747.
Fuehrer, M., Römisch, K., 1977. Effects of modern ship traffic on inland and ocean waterways and their structures. In: PIANC 24th Congr, pp. 1-3.

Fuehrer, M., Pohl, H., Römish, K., 1987. Propeller jet erosion and stability criteria for bottom protections of various constructions. Bull. Perm. Int. Assoc. Navig. Congr. 58.

Fuehrer, M., Römisch, K., Engelke, G., 1981. Criteria for dimensioning the bottom and slope protections and for applying the new methods of protecting navigation canals. In: 25th International Navigation Congress, Permanent International Association of Navigation Congresses.

Gaythwaite, J.W., Drive, A.B., 2004. Design of Marine Facilities for the Berthing , Mooring, and Repair of Vessels.

Hamill, G., 1987. Characteristics of the Screw Wash of a Manoeuvring Ship and the Resulting Bed Scour. Queen's University of Belfast.

Hamill, G., Johnston, H.T., Stewart, D., 1999. Propeller wash scour near quay walls. J. Waterw. Port, Coast. Ocean Eng. 125, 170-175.

Hashmi, H., Johnston, H.T., Hamill, G., 1992. Propeller wash induced erosion considerations in the design of berth structures. In: Proceedings of the Ports 2000 Conference. An International Conference on Port Development for the Next Millennium, pp. 3-6. Hong Kong.

Hayes, D.F., Chintamaneni, R., Bommareddy, P., Cherukuri, B., 2006. Propwash impacts on water quality around dredging and other marine construction activities. In: 26th Annual WEDA Conference, pp. 17-26. San Diego, U.S.A.

Jiang, J., Lam, W.H., Cui, Y., Zhang, T., Sun, C., Guo, J., Ma, Y., Wang, S., Hamill, G., 2019. Ship twin-propeller jet model used to predict the initial velocity and velocity distribution within diffusing jet. KSCE J. Civ. Eng. 23, 1118-1131. https://doi.org/ 10.1007/s12205-019-1370-x.

Kim, E.K., Jeong, J.S., Park, G., Im, N.K., 2012. Characteristics of Ship Movements in a Fairway, 12, 285-289.

Molland, A.F., 2011. The Maritime Engineering Reference Book: a Guide to Ship Design, Construction and Operation. Elsevier.

Mujal-Colilles, A., Castells, M., Llull, T., Gironella, X., Martínez de Osés, X., 2018. Stern twin-propeller effects on harbor infrastructures. Experimental analysis. Water 10. https://doi.org/10.3390/w10111571.

Mujal-Colilles, A., Gironella, F.X., Sanchez-Arcilla, A., Puig Polo, C., Garcia-Leon, M., 2017. Erosion caused by propeller jets in a low energy harbour basin. J. Hydraul Res. 55, 121-128. https://doi.org/10.1080/00221686.2016.1252801.

Mujal-Colilles, A., Gironella, X., Crespo, A., Sanchez-Arcilla, A., 2017. Study of the bed velocity induced by twin propellers. J. Waterw. Port, Coast. Ocean Eng. 143, 04017013 https://doi.org/10.1061/(ASCE)WW.1943-5460.0000382.

PIANC, 2015. Guidelines for Protecting Berthing Structures From Scour Caused By Ships. Report $n^{\circ} 180$. The World Association for Waterborne Transportation Infrastructure.

Puertos del Estado, 2012. Obras de Atraque y Amarre: Criterios generales y Factores del Proyecto (R.O.M. 2.0-11). 
Römisch, K., Hering, W., 2002. Input data of propeller induced velocities for dimensioning of bed protection near quay walls. Bull. Perm. Int. Assoc. Navig. Congr.

Ryan, D., 2002. Methods for Determining Propeller Wash Induced Scour in Harbours. Queen's University of Belfast.

Ryan, D., Hamill, G.A., Johnston, H.T., 2013. Determining propeller induced erosion alongside quay walls in harbours using artificial neural networks. Ocean Eng. 59, 142-151. https://doi.org/10.1016/j.oceaneng.2012.10.018.

Savitzky, A., Golay, M.J.E., 1964. Smoothing and differentiation of data by simplified least squares procedures. Anal. Chem. 36, 1627-1639. https://doi.org/10.1021/ ac60214a047.

Silveira, P.A.M., Teixeira, A.P., Soares, C.G., 2013. Use of AIS data to characterise marine traffic patterns and ship collision risk off the coast of Portugal. J. Navig. 66 879-898. https://doi.org/10.1017/S0373463313000519.

Stewart, D.P.J., 1992. Characteristics of a Ship's Screw Wash and the Influence of Quay Wall Proximity. Dr. Diss. Queen's Univ. Belfast.

Tan, R.İ., Yüksel, Y., 2018. Seabed scour induced by a propeller jet. Ocean Eng. 160 132-142. https://doi.org/10.1016/j.oceaneng.2018.04.076.
Verheij, H., 1983. Comparison of water jets and conventional propeller jets. Waterloopkundig Laboratorium.

Verhey, H., 1983. The stability of bottom and banks subjected to the velocities in the propeller jet behind ships. In: Int. Harb. Congr. 8th.

Wang, T.S., Whelan, M., Keith, D., Verduin, J., Brown, P., 2006. Design of the Campbell shipyard sediment remediation project, San Diego, California. In: 26th Annual WEDA Conference, pp. 309-322. San Diego, U.S.A.

Wei, M., Chiew, Y.-M., Guan, D., 2018. Temporal development of propeller scour around a sloping bank. J. Waterw. Port, Coast. Ocean Eng. 144, 06018005 https://doi.org/ 10.1061/(ASCE)WW.1943-5460.0000465.

Wei, M., Chiew, Y.M., 2019. Impingement of propeller jet on a vertical quay wall. Ocean Eng. 183, 73-86. https://doi.org/10.1016/j.oceaneng.2019.04.071.

Yew, W.T., Hashim, R., Ng, K.C., 2017. Experimental investigation of scour induced by twin-propeller wash. Ournal Waterw. Port, coastal. Ocean Eng. 143 (4), 1-10. https://doi.org/10.1061/(ASCE)WW.1943-5460.0000387, 04017006.

Yuksel, Y., Tan, R.I., Celikoglu, Y., 2019. Determining propeller scour near a quay wall. Ocean Eng. 188, 106331. https://doi.org/10.1016/J.OCEANENG.2019.106331. 